\title{
Supremo Tribunal Federal e COVID-19: entre informação e saúde
}

\author{
Supreme Federal Court and COVID-19: \\ between information and health
}

\author{
Anderson Carlos Bosa \\ Universidade de Santa Cruz do Sul - UNISC \\ Rosana Helena MaAs \\ Universidade de Santa Cruz do Sul - UNISC
}

Resumo Considerando a atual crise sanitária global causada pelo novo Coronavirus Disease (COVID-19), pretende-se verificar como o direito à informação age na proteção do direito à saúde e auxilia no enfrentamento da pandemia. Assim, analisa-se o posicionamento do Supremo Tribunal Federal (STF) frente ao fornecimento de dados correlacionados ao COVID-19 por meio da Ação Direta de Inconstitucionalidade (ADI) n. 6351, 6347, 6353 e da Medida Cautelar na Arguição de Descumprimento de Preceito Fundamental (ADPF) n. 690, buscando-se, ao final, responder a seguinte problemática: qual é o posicionamento do STF em relação ao direito à informação na proteção do direito à saúde na atual crise sanitária vivenciada pelo Brasil por conta do COVID-19? Para objetar tal problemática, utiliza-se do método dedutivo e da técnica de pesquisa bibliográfica e jurisprudencial. Constata-se que o STF se posiciona no sentido de que o direito à informação não pode ser limitado quanto ao seu caráter de acesso, sendo importante pressuposto para a proteção do direito à saúde, pois a coleta de dados epidemiológicos relacionada ao COVID-19 constitui mecanismo essencial para a tomada de decisões, alocação de recursos, efetividade de políticas públicas e ações de vigilância epidemiológicas. Ainda, o sigilo de informações deve ser medida excepcional quando determina o interesse público, não podendo transformar a exceção (o sigilo) em regra. A importância do trabalho está direcionada ao fator da necessidade de compreender como a proteção ao direito à saúde é sistêmica, abrangendo outros direitos previstos pelo ordenamento jurídico nacional, sendo um deles, o direito à informação.

Palavras-chave: COVID-19; Direito à InformaÇão; Direito À Saúde; Supremo TriBUNAL FEDERAL.

ABSTRACT: Considering the actual global sanitary crisis caused by the new Coronavirus Disease (COVID-19), it is intended to verify how the right to information act in the protection of the right to health and helps to face the pandemic. Thus, the position of the Supreme 
Federal Court (STF) regarding the supply of data correlated to COVID-19 through Direct Actions of Unconstitutionality (ADI) n. 6351, 6347, 6353 and the Precautionary Measure in the Compliance with Fundamental Precepts (ADPF) n. 690, seeking, in the end, to answer the following problem: what is the STF's position in relation to the right to information in the protection of the right to health in the current health crisis experienced by Brazil due to COVID-19? To object to this problem, the deductive method and the bibliographic and jurisprudential research technique are used. It appears that the STF is positioned in the sense that the right to information cannot be limited as to its character of access, being an important assumption for the protection of the right to health, since the collection of epidemiological data related to COVID-19 constitutes essential mechanism for decision-making, resource allocation, public policy effectiveness and epidemiological surveillance actions. Still, the confidentiality of information must be an exceptional measure when it determines the public interest, and cannot make the exception (confidentiality) a rule. The importance of work is directed to the need factor to understand how the protection of the right to health is systemic, covering other rights provided for by the national legal system, one of which is the right to information.

Keywords: COVID-19; Direct to Information; Direct to Health; Federal Court OF JUSTICE.

\section{INTRODUÇÃo}

Dentro do contexto histórico da humanidade, é possível analisar as ocorrências de diversos problemas sanitários causados pelas mais diversas doenças, tais como: a Gripe Espanhola (1918-1919), Gripe Asiática (1957-1958) e Gripe Russa (1889-1890). Atualmente, vivencia-se a maior crise pandêmica global do século XXI causada pelo COVID-19, na qual a evolução dos casos, índices de transmissão, análise dos grupos de maior risco, leitos ocupados, taxa de recuperação e óbitos, resultantes do vírus, adicionado ao fato da inexistência de uma vacina pré-existente ou medicamentos com atuação específica à doença, compreendem um conjunto de informações essenciais para a tomada de decisões e aplicação de políticas de contingência da enfermidade e proteção ao direito à saúde.

Esse conjunto de informações que se desenvolve na testagem, perpassa pelas hospitalizações, pacientes recuperados e óbitos ocorridos, é registrado e, nas melhores hipóteses, utilizado para fundamentar diversas tomadas de decisões políticas, sociais e científicas para elaborações de respostas, alocações de investimentos e observações da eficácia de ingerências, como políticas públicas de distanciamento social, de instalação de novos leitos e o uso de medicamentos e tratamentos médicos hospitalares em pacientes infectados.

À vista disso, o direito à saúde e o direito à informação são consagrados pelo ordenamento constitucional como direitos fundamentais. A Carta Magna de 1988 proclama, no caput de seu artigo 102, que cabe ao STF à tarefa de seu guardião máximo, cumprindo-lhe, ainda, dizer a última palavra em sede de interpretação das disposições constitucionais e seus conflitos, decidindo-os com base nos princípios constitucionais, principalmente, garantindo os direitos fundamentais. 
Considerando essas exposições introdutórias, o presente trabalho passa, de início, a estudar o direito à informação e sua correlação na proteção do direito à saúde, para, posteriormente, verificar o posicionamento do STF frente ao fornecimento de dados correlacionados ao COVID-19 por meio da ADI n. 6351, 6347, 6353, ajuizada por conta da Medida Provisória n. 928/2020, e da Medida Cautelar na ADPF n. 690.

Dessa forma, utilizando-se do método dedutivo, da técnica de pesquisa bibliográfica e jurisprudencial, almeja-se responder a seguinte problemática: qual é o posicionamento do STF em relação ao direito à informação na proteção do direito à saúde na atual crise sanitária vivenciada pelo Brasil por conta do COVID-19? A importância do presente trabalho está direcionada ao fator da necessidade de compreender como a proteção ao direito à saúde é sistêmica, abrangendo outros direitos previstos pelo ordenamento jurídico nacional, sendo, um deles, o direito à informação.

\section{ENTRE INFORMAÇÃO E SAÚDE: O DIREITO DE ACESSO À INFORMAÇÃo COMO PRESSUPOSTO À PROTEÇÃO DO DIREITO À SAÚDE}

Os direitos fundamentais se destacam com o constitucionalismo do século XVIII, conquanto existam registros relevantes de antecedentes históricos para a normatização desses direitos (FERRARI et al., 2016). No Brasil, a Constituição Federal de 1988 consagra-se como marco substancial no prognóstico dos direitos fundamentais, apresentando o direito à saúde como direito e garantia fundamental social no artigo $6^{\circ}$ e como elemento da ordem social, ao lado do desenvolvimento da sociedade brasileira, no artigo 196 (MAAS; BOSA, 2020. Já o direito fundamental à liberdade de informação está positivado no artigo $5^{\circ}$, incisos XIV e XXXIII e no artigo 220 da Carta Magna (BRASIL, 1988).

A liberdade de informação abrange a busca, o acesso, o recebimento e a difusão de informações ou ideias através de qualquer meio, em que não existe dependência de censura. É circunstancial entender que o direito de acesso à informação ${ }^{1}$ não se confunde com o direito de liberdade de expressão, como muitas vezes ocorre, pois, enquanto na liberdade de expressão o cidadão possui o direito de explanar seus pensamentos e ideias de forma livre, desde que não seja para fins ilícitos, no acesso à informação o cidadão busca obter informações quanto à atividade da Administração Púbica (SILVA, 2014).

Para sua conceituação, a Organização das Nações Unidas (ONU), no ano de 2004, por meio da Declaração Conjunta sobre Direito de Acesso à Informação e sobre Legislação que Regula o Sigilo, consagra o direito à informação como sendo uma previsão que:

[...] constitui um direito humano fundamental que deve ser efetivado em nível nacional através de legislação abrangente [...] baseado no princípio da máxima divulgação, estabelecendo a presunção de que toda informação é acessível e está sujeita somente a um sistema estrito de exceções (MENDEL, 2009, p. 10).

\footnotetext{
Aqui, vale o destaque enquanto ao uso da terminologia "direito à informação", considerando que o direito ao acesso à informação estava, em legislações passadas, entrelaçado aos termos "liberdade de informação" e "liberdade de expressão". Tal parâmetro de mudança se deu pela Lei Indiana de 2005, a qual concede acesso às informações em posse de órgãos públicos, ou seja, muda o termo de "liberdade" para "acesso" (MENDEL, 2009).
} 
No que tange ao direito à saúde, esse é um dos principais direitos fundamentais sociais encontrados na Lei Maior brasileira, está diretamente interligado ao princípio que norteia todo o arcabouço jurídico pátrio, qual seja: o princípio da dignidade da pessoa humana fato pelo qual esse direito obtém tratamento especial (CURY, 2005). Dito isso, saúde é uma obrigação do Estado, garantida por meio de políticas sociais e econômicas que busquem à diminuição do risco de doenças e outros agravos, bem como o acesso universal e igualitário às ações e serviços para sua ascensão, proteção e recuperação, cabendo ao Poder Público dispor sobre a sua regulamentação, fiscalização e controle (MORAES, 2003).

Nessa perspectiva, a dimensão constitucional do direito à informação representa uma peculiaridade da dignidade da pessoa humana, visto que, por meio de informações de qualidade, derivadas de fontes confiáveis, os cidadãos exercem seu direito de autodeterminação (STROPPA, 2010). Além disso, tais informações podem ser utilizadas em variados âmbitos da sociedade e, no que se remete à efetivação e tutela do direito à saúde, esses dados acabam por refletir nas tomadas de medidas, sejam elas particulares, no que se pressupõe em como se portar e quais decisões tomar diante de um cenário de crise sanitária a fim de proteger sua saúde ou, então, de entes públicos no que se remete às mais diversas ações governamentais de prevenção, atuação e proteção ao direito à saúde.

De outra banda, evidencia-se o direito à informação como instrumento indispensável à fiscalização e responsabilização do governo (NOVELINO, 2013); considerando que o ordenamento constitucional é insculpido pelo princípio da publicidade ${ }^{2}$ como um dos vetores imprescritíveis à Administração Pública, à publicidade e à transparência correspondem à obrigatoriedade do Estado em fornecer informações, sob pena de responsabilização política, civil e criminal, salvo nas hipóteses constitucionais de sigilo (LIMBERGER, 2008).

No mesmo sentido, o livre fluxo de informações, dados e ideias preenche um espaço de destaque na democracia, é essencial para o real respeito aos direitos humanos e fundamentais. Uma vez que esse direito compreendido como o direito de buscar, receber e transmitir informações e ideias, não é respeitado, violações de direitos humanos são cometidas em segredo, ocorre um fomento à corrupção e se abre um espaço maior para a ineficiência dos governos (KAHN, 2009). Posto que, "uma das formas mais eficazes de atacar a má governança, sobretudo com o passar do tempo, é por meio de um debate aberto e bem informado" (MENDEL, 2009, p. 5).

Nesse contexto, a participação dos cidadãos em uma democracia representativa só se fortalece em um âmbito de completa perceptibilidade e viabilidade da exibição crítica acerca das políticas públicas empregadas pelos representantes do povo. À vista disso, Holmes Jr. (1988) sustenta, com base no seu conhecido pragmatismo, a indispensabilidade do emprego da política de desconfiança na construção do raciocínio individual e na autodeterminação democrática para o autossuficiente desempenho dos direitos de voto e contestação; além da imprescritível necessidade de fiscalização dos órgãos governamentais que só se torna possível com a garantia da publicidade e transparência. Esse caráter fiscalizador

2 Considerando a prevalência do princípio da publicidade dos atos administrativos no ordenamento brasileiro, valido pelo Art. 37, caput, da Constituição Federal, estabelece que: "Art. 37. A administração pública direita e indireta de qualquer dos Poderes da União, do Estado, do Distrito Federal e dos Municípios obedecerá aos princípios de legalidade, impessoalidade, moralidade, publicidade e eficiência" [...] (BRASIL, 1988, http://www.planalto.gov.br/ccivil_03/constituicao/constituicao.htm). 
das informações, a exemplo, serve como base de verificação de como, onde e o porquê são aplicados determinados investimentos nas políticas de saúde.

Ademais, o direito de acesso à informação configura uma obrigação da Administração Pública e um direito subjetivo do indivíduo e da sociedade (MARTINS JÚNIOR, 2010). Assim, entendendo a dinâmica fundamental e humanitária do direito à saúde e seus mecanismos de proteção, ao Estado, depreende-se uma obrigação positiva e subjetiva de propiciar que o cidadão usufrua de acesso à informação sobre qualquer violação de direitos humanos e fundamentais (como, por exemplo, a não prestação adequada de serviços públicos de saúde; erros por parte do Estado eivados de imprudência, imperícia ou negligência; negativa na prestação do direito à saúde; medidas contrárias às recomendadas por reconhecidos órgãos nacionais e internacionais não só no enfrentamento à COVID-19, mas também de diversas outras doenças; entre outros fatos violadores diretos ou indiretos de direitos humanos e fundamentais).

Em complemento, o direito fundamental ${ }^{3}$ de acesso à informação amplifica-se em nossa ordem jurídica em três níveis: o direito de informar, o direito de se informar e o direito de ser informado. O primeiro se estrutura na liberdade de repassar ou comunicar informações a terceiros, de as proliferar sem restrições, da mesma maneira, pode se encampar de forma positiva enquanto direito à informar, em outros termos, direitos a meios para informar. $\mathrm{O}$ direito de se informar se molda, especialmente, na liberdade de buscar informações, de pesquisa de fontes, isto é, no direito de não ser impedido de se informar. $\mathrm{E}$ o direito de ser informado é a versão positiva do direito de se informar, emoldando-se em um direito a ser mantido apropriadamente e realmente informado, desde já, pelas formas de comunicação e pelos poderes públicos (CANOTILHO et al., 1993).

Nesse ínterim, ao estudar as garantias dos direitos, discorre-se sobre o poder político que é assentado pelo direito mutuamente. Isso indica um nexo que ocasiona a instrumentalização do direito para o exercício estratégico e dinâmico do poder. Habermas (2012) escreve sobre a ideia de que o Estado de Direito exige como contrapartida - uma organização estrutural do Poder Público que vincula o Poder Político - alicerçado conforme o direito, a se legitimar, por sua vez, pelo direito legitimamente instituído. Com isso, no sistema da Administração Pública, aplica-se um poder que necessita se (re) estruturar progressivamente partindo do poder comunicativo, pois o direito não é apenas característico para o código do poder o qual direciona o processo de administração: ele institui o meio para a transformação do controle comunicativo em administrativo. Aqui, é possível obter a ideia do Estado de Direito na percepção em que o direito legítimo é produzido por meio do poder de comunicação que, por seu turno, é modificado em poder administrativo pelo direito legitimamente normatizado.

Nessa ordem, o Estado Democrático de Direito manifesta-se por meio do terreno jurídico e político, o que ocasiona o desenvolvimento de ações sociais e políticas. Diante disso, o Estado de Direito estrutura-se pela ordem jurídica, abarcando o direito à informação que

\footnotetext{
3 O direito à informação é considerando direito fundamental não apenas pelo ordenamento constitucional doméstico, mas é tratado da mesma forma pela Corte Interamericana de Direitos Humanos, pela Convenção Americana sobre Direitos Humanos, pelo Conselho da Europa, dentro outros órgãos internacionais de proteção dos direitos fundamentais (MENDEL, 2009).
} 
não se restringe ao mero aspecto moral, mas também formal e material. Cabendo aos entes da federação avaliar que seu poder administrativo cria um espaço de construção sobre os caminhos e decisões a serem tomadas em relação à sociedade e governo, garantindo - por meio da informação — um espaço de discussão de questões as quais cercam toda a sociedade e que alberga a materialização dos planos de executividade e avaliação dos temas oportunos. Com essa ideia, e a fim de realizar e regulamentar o direito fundamental à livre informação, transformando o poder comunicativo em administrativo, criou-se a Lei de Acesso à Informação (LAI) n. 12.527/20114.

Como principais antecedentes normativos a LAI, tem-se: a Lei n. 9.051/95, a qual se dispõe sobre a expedição de certidões para a proteção de direitos e elucidações de circunstâncias; a Lei n. 9.057/97, a qual pretendeu regular o habeas data e o acesso à informação, viabilizando o acesso ao banco de dados públicos sobre informações pertinentes ao próprio cidadão; o artigo $2^{\circ}$, § único, inciso $\mathrm{V}$, da Lei n. 9.784/99, o qual regula o processo administrativo na esfera da Administração Pública Federal, no qual consta que, nos processos administrativos, deverá ser observado, entre outros requisitos, a "divulgação oficial dos atos administrativos, resguardadas as hipóteses de sigilo previstas na Constituição” (HEINEN, 2015).

Seguimos a Lei Complementar 101/2000, reconhecida como Lei de Responsabilidade Fiscal, a qual estipula normas de finanças públicas, apresentando mecanismos de transparência da gestão fiscal do Poder Executivo, do Poder Legislativo (aqui abrangendo os Tribunais de Contas), do Poder Judiciário e do Ministério Público, bem como das respectivas administrações diretas, fundos, autarquias, fundações e empresas estatais dependentes; e a Medida Provisória n. 2.143-31/2001, a qual criou a Controladoria-Geral da União, regulada pela Lei n. 10.683/03, a qual compõe atribuições quanto aos assuntos que, no terreno do Poder Executivo, são relativos à defesa do patrimônio público e ao incremento da transparência da gestão por meio de ações internas de controle, tais como auditoria pública, correição, prevenção, combate à corrupção e ouvidoria (HEINEN, 2015).

A LAI passou a prever os procedimentos que necessitam ser respeitados pela Administração Pública com o foco de concretizar o acesso à informação. O respectivo ordenamento legal prevê como diretrizes a organização da participação popular frente às informações disponibilizadas pelos órgãos públicos e a construção de estruturas que possibilitem a criação de canais de acesso dessas informações (SEABRA et al., 2012). Nessa exegese, Bitencourt e Reck (2016, apud ARAUJO, 2004), ao citar a doutrina de Araújo, descrevem que:

[...] só se pode investir alguém no direito de receber informações quando simultaneamente atribuir-se a outrem o dever de informar. Nessa matéria, a Constituição Federal foi terminante ao atribuir exclusivamente ao Poder Público (art. $5^{\circ}$, XXXIII, e 37, caput) o dever de informar. Assim sendo, pode-se concluir que o direito de ser informado assume dois sentidos. Primeiro, o direito de receber as informações veiculadas sem interferência estatal, numa interface com

\footnotetext{
4 No ano de 1990 apenas 13 países possuíam, em seu ordenamento jurídico, leis de acesso à informação, até o ano de 2016; esse número já representava mais de 70 Estados. Ainda, em 1990, nenhuma organização intergovernamental reconhecia o direito à informação; agora existem diversas instituições financeiras internacionais que adotam políticas de divulgação de informações. Da mesma forma que, até o mesmo ano, existia uma visão predominante do direito de informação como um meio de governança administrativa e não como um direito humano fundamental, como é entendido atualmente (MENDEL, 2009).
} 
o direito de informar. Segundo, o direito de ser mantido constantemente informado sobre os negócios e atividades públicas (BITENCOURT; RECK, 2016, apud ARAUJO, 2004)

Em conformidade com o texto da LAI, a regulamentação do acesso à informação envolve procedimentos indispensáveis que garantem esse direito, sendo imprescindível que sejam executados de acordo com os princípios básicos da Administração Pública, com escopo em promover a publicidade como preceito geral e o sigilo como exceção. No que se designa as informações de interesse público, em conformidade com a LAI, essas deverão ser divulgadas livremente pelas instituições, mesmo que não sejam solicitadas (KRAMER et al., 2015).

Para isso, faz-se necessário o uso de meios de comunicação disponibilizados pela tecnologia da informação, assegurando um mecanismo que promova a segurança dos dados para que o sistema não seja invadido e modificado. O corpo legislativo da LAI, apresenta dispositivos para o estímulo ao progresso da cultura de transparência na Administração Pública, devendo ser adotados procedimentos que sejam aderidos voluntariamente pelas instituições, respeitando o desenvolvimento do controle social da Administração Pública (BRASIL, 2011).

Ademais, o complexo normativo da LAI conceitua o conjunto de informações como sendo ações direcionadas à produção, transporte, transmissão, distribuição, arquivamento, armazenamento, eliminação, avaliação, destinação ou controle da informação, dentre outras. Para isso, tendo o Estado o dever de garantir o direito de acesso à informação, a LAI prevê que o acesso deve obedecer a procedimentos eficazes, transparentes, objetivos e de fácil compreensão. Sendo obrigatório, segundo seu artigo $9^{\circ}$, a divulgação em sites oficiais da internet (BRASIL, 2011).

Outro aspecto importante da LAI é a imposição da transparência ativa e passiva na Administração Pública. A primeira é entendida como a obrigação de órgãos e entidades públicas de divulgar, de maneira espontânea, independente de terem sido requisitadas, informações de interesse geral. A segunda, refere-se à criação dos Serviços de Informação do Cidadão (SIC), ou seja, é um canal efetivo em que a sociedade pode apresentar à Administração Pública sua demanda de informação (KRAMER et al., 2015).

Em consonância com o Decreto $n^{\circ} 7.724$, de 16 de maio de 2012, o qual regula a LAI, o Capítulo III, ao falar sobre a transparência ativa, determina que as informações deverão ser disponibilizadas em sites oficiais da internet de órgãos públicos e entidades públicas independentemente de requerimentos. O Capítulo IV do Decreto trata da transparência passiva compreendendo o SIC como forma de fornecer, orientar e atender o público; informar sobre o trâmite de documentos; e receber e realizar o registro de pedidos de acesso à informação (BRASIL, 2012).

Conseguinte, a LAI estabelece, em seu artigo 11 (BRASIL, 2011), que o "órgão ou entidade pública deverá autorizar ou conceder o acesso imediato à informação disponível", posto que, se não for viável fornecer o acesso imediato, o órgão ou entidade requerida deverá, em um prazo máximo de vinte dias, podendo ser prorrogado por mais dez dias mediante justificativa expressa, (i) comunicar data, local e modo para a realização da consulta, consumar sua reprodução ou obter certidão; (ii) evidenciar as razões de fato ou de direito da recusa total ou parcial do acesso pretendido; ou (iii) indicar que não possui a informação solicitada. 
Em caso de indeferimento de acesso à informação, a LAI estipula prazo de dez dias a contar da sua ciência para propositura de recurso pelo interessado, devendo à autoridade hierarquicamente superior se manifestar em um prazo de cinco dias. Após manifestação da autoridade hierarquicamente superior, no caso de recusa ao acesso à informação pelos órgãos ou entidades do Poder Executivo Federal, o solicitante poderá recorrer à Controladoria-Geral da União que deliberará no prazo de cinco dias se (i) a disponibilização da informação não classificada como sigilosa; (ii) a decisão de negativa de acesso à informação total ou parcial classificada como sigilosa não indicar a autoridade classificadora ou a hierarquicamente superior a quem possa ser direcionado pedido de acesso ou desclassificação; (iii) os procedimentos de classificação de informação sigilosa estabelecidos pela LAI não tiverem sido observados; e (iv) estiverem sendo descumpridos prazos ou demais procedimentos da LAI (BRASIL, 2011).

O artigo 21, da LAI, também prevê a impossibilidade de negação ao acesso as informações necessárias à tutela judicial ou administrativa de direitos fundamentais. Da mesma forma que classifica, em seu artigo 23, a informação quanto ao grau e prazos de sigilo que são exceções dentro da publicidade e transparência, determinando no artigo 24 essas informações como ultrassecretas pelo prazo de vinte e cinco anos, secretas pelo prazo de quinze anos ou reservadas pelo prazo de cinco anos (BRASIL, 2011).

Diante de todo o exposto, ao estudar o direito à informação, observa-se que a pandemia causada pela COVID-19 tem produzido uma quantidade massiva de dados. Na medida em que os mais diversos países buscam construir cenários realistas, observando o concreto nível do problema, as entidades científicas realizam coletas de dados e sistematizam informações sobre a atuação do vírus, empreendendo esforços de modelagem a fim de presumir a carga pandêmica e as necessidades de prestações de saúde.

Portanto, é possível dimensionar a importância da divulgação de dados e informações correlacionados à COVID-19, como sendo ferramentas fundamentais na execução de respostas, alocação de recursos financeiros e técnicos e avaliação de eficácia de intervenções, além de ser um direito fundamental, atuando aqui, como pressuposto de outros direitos fundamentais, no caso, o direito à saúde e à vida.

Com isso, não existem dúvidas de que a disponibilidade de dados de forma aberta e transparente, respeitando os princípios e direitos constitucionais, aparece como fundamental para combater a pandemia. Entretanto, alguns entraves impostos por decisões políticas e administrativas têm causado determinadas limitações ao acesso às informações e ações em saúde no Brasil correlacionadas ao vírus, exigindo uma atuação contundente por parte do judiciário na garantia do dever ao acesso à informação.

Posto isso, o presente trabalho passa a dissertar sobre o posicionamento do STF em relação à divulgação de dados relacionados à COVID-19, tendo em vista as ADIs n. 6351, 6347, 6353, provenientes da edição da Medida Provisória n. 928/20 e que, entre outros pontos, alterou a observância de prazos na disponibilidade de informações, modificou o modo de recurso em caso de negativa e criou outros empecilhos, e da Medida Cautelar na ADPF n. 690, que atacou decisão do Ministério da Saúde o qual alterou a forma de disponibilização do balanço diário de dados correlacionados ao vírus. 


\section{O POSICIONAMENTO DO STF COM RELAÇÃo à DIVULGAÇÃO DE DADOS COR- RELACIONADOS à Covid-19}

Em 11 de março de 2020, a Organização da Saúde (OMS) declarou como pandemia a doença causada pela COVID-19. Devido à situação de desconhecimento dos mais diversos fatores da doença, tais como as formas de contágio, método de prevenção, vacinas, entre outros, bem como instrumentos para o auxílio no tratamento e na cura, emergem medidas não farmacêuticas criadas pelo Estado com o escopo de enfrentar o atual cenário sanitário crítico social (UCHÔA et al., 2020).

O governo brasileiro, procurando combater a situação causada pela doença, emitiu diversos dispositivos legais em resposta ao vírus e à crise por esse causada, buscando enquadrar a sociedade brasileira no atual cenário de pandemia mundial. Houve uma forte movimentação legislativa, tanto no âmbito federal, estadual e municipal, tendo destaque a produção da Lei n. 13.979, de 06 de fevereiro de 2020, a qual se dispõe sobre as medidas para enfrentamento da emergência de saúde pública decorrente da COVID-19 (BRASIL, 2020a).

Em seguida, o governo federal criou a Medida Provisória n. 928 de 28 de março de 2020 que - como se verá a seguir - fora suspensa por decisão do STF e, dentre outros pontos, incluiu por meio do seu artigo $1^{\circ}$ o artigo $6^{\circ}$-B no texto da Lei n. 13.979/20 o qual modifica a LAI, alterando prazos de respostas, disposições em relação aos recursos nos casos de negativas de acesso à informação, entre outros empecilhos que dificultam o acesso à informação. De acordo com o texto do respectivo dispositivo:

Art. $6^{\circ}$-B. Serão atendidos prioritariamente os pedidos de acesso à informação,
de que trata a Lei $n^{\circ} 12.527$, de 2011 , relacionados com medidas de enfren-
tamento da emergência de saúde pública de que trata esta Lei. $\S 1^{\circ}$ Ficarão
suspensos os prazos de resposta a pedidos de acesso à informação nos órgãos
ou nas entidades da administração pública cujos servidores estejam sujeitos
a regime de quarentena, teletrabalho ou equivalentes e que, necessariamente,
dependam de: I acesso presencial de agentes públicos encarregados da resposta;
ou II agente público ou setor prioritariamente envolvido com as medidas de en-
frentamento da situação de emergência de que trata esta Lei. $\S 2^{\circ}$ Os pedidos de
acesso à informação pendentes de resposta com fundamento no disposto no $\S 1^{\circ}$
deverão ser reiterados no prazo de dez dias, contado da data em que for encerra-
do o prazo de reconhecimento de calamidade pública a que se refere o Decreto
Legislativo ${ }^{\circ} 6$, de 20 de março de $2020 . \S 3^{\circ}$ Não serão conhecidos os recursos
interpostos contra negativa de resposta a pedido de informação negados com
fundamento no disposto no $\S 1^{\circ}$. $\S 4^{\circ}$ Durante a vigência desta Lei, o meio legí-
timo de apresentação de pedido de acesso a informações de que trata o art. 10
da Lei ${ }^{\circ} 12.527$, de 2011 , será exclusivamente o sistema disponível na internet.
$\S 5^{\circ}$ Fica suspenso o atendimento presencial a requerentes relativos aos pedidos
de acesso à informação de que trata a Lei ${ }^{\circ} 12.527$, de 2011 (BRASIL, 2020a).

Segundo informações divulgadas pela Controladoria-Geral da União, a Medida Provisória que incluiu o artigo $6^{\circ}$-B, na Lei n. 13.979/20, justificar-se-ia pela abrangência nacional da LAI, "estando muitas prefeituras do país em situação delicada de pessoal". Também mencionando que os prazos da LAI seriam observados quando for possível a formatação de resposta digital (BRASIL, 2020b). 
Tendo em vista os questionamentos de inconstitucionalidade do mencionado dispositivo, foram protocoladas três Ações Diretas de Inconstitucionalidades junto ao STF, buscando a suspensão da norma trazida pela Medida Provisória 928, quais sejam: ADI 6347, ADI 6351 e ADI 6353.

Na ADI n. 6347, ajuizada pelo Partido Rede Sustentabilidade, fundamentou-se que o

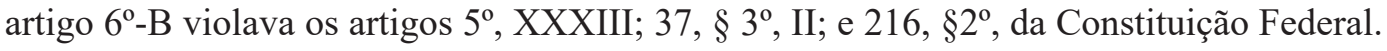
Ademais, foi alegado que o dispositivo restringia o direito à informação por (i) suspender os prazos de resposta a requerimentos de acesso à informação; (ii) impossibilitava o conhecimento de recursos protocolados contra essa negativa de resposta; e (iii) tornava mais difícil seu posterior acesso, por demandar a necessidade de reiteração do requerimento quando cessado o estado de calamidade pública. Por fim, aduziu que a nova regra mitigava o controle social às ações públicas por se configurar como um obstáculo desproporcional e não razoável ao direito de acesso à informação (BRASIL, 2020c).

Adiante, tem-se a proposta pelo Conselho Federal da Ordem dos Advogados do Brasil (CFOAB), a ADI n. 6351, o qual impugnou a nova regra por considerar que a mesma violava os artigos $2^{\circ} ; 5^{\circ}$, XXXIII; 37, §3 $3^{\circ}$ II; 62, caput; e 216, $\S 2^{\circ}$, da Constituição Federal. Da mesma forma, sustenta a inconstitucionalidade formal e material do dispositivo (BRASIL, 2020c).

No que se refere ao vício formal, aludia que a LAI já apresentava em seu artigo 11, § $1^{\circ}$, II, norma a ser aplicável em um cenário de crise como a vivenciada pela COVID-19, o que afastaria a necessidade de atropelamento do devido processo legislativo para a edição da Medida Provisória. De outra banda, mencionava a inexistência de motivos em comprovar os requisitos do artigo 62, caput, da Carta Mana (relevância e urgência) (BRASIL, 2020c).

Materialmente, a ADI n. 6351 argumentava que por (i) suspender os prazos de respostas a requerimentos de acesso à informação; (ii) contrapor o devido processo legal ao vetar o conhecimento de recursos protocolados contra essa negativa de resposta; (iii) instituir obrigação excessiva ao cidadão por exigir a reiteração do pedido quando cessada a calamidade provocada pela COVID-19; e (iv) existir forma menos gravosa de lidar com o respectivo tema em circunstâncias como as causadas pela COVID-19 prevista na LAI, a Medida Provisória limitaria os direitos constitucionais à informação, à transparência e à publicidade (BRASIL, 2020c).

Já a ADI n. 6353, protocolada pelo Partido Socialista Brasileiro (PSB), alegava a inconstitucionalidade da matéria por ofensa aos artigos $5^{\circ}$, XXXIII, XXXIV, LIV e LV; e 37, caput e $\S 3^{\circ}$, II, da Constituição Federal. Justificando que a regra acaba por impedir a aplicação da LAI a setores da Administração Pública ao (i) impedir de forma ilógica o acesso à informação; (ii) flexibilizar o dever da Administração Pública de efetivar o acesso à informação; e (iii) retirar a possibilidade de recurso contra atos que denegarem resposta às solicitações com base na LAI (BRASIL, 2020c).

Diante das referidas alegações, o STF, por meio da relatoria do Ministro Alexandre de Moraes, concedeu, em julgamento conjunto, Medida Cautelar a todas as ADIs, suspendendo a eficácia do artigo $6^{\circ}$-B, da Lei n. 13.979/20. O voto proferido pelo Ministro também foi no sentido de referendar a Medida Cautelar deferida sob o argumento de que na hipótese da norma objeto das ações, essa transformava a exceção — sigilo de informações - em 
regra, afastando a aplicação dos princípios da publicidade e da transparência. Além disso, a publicidade específica de determinada informação só poderá ser negada em caso de pleno interesse público. Nesse caso, a Administração Pública tem a obrigação de manter transparência absoluta nos negócios públicos, isso sob pena de desrespeito aos artigos 37, caput, e $5^{\circ}$, incisos XXXIII e LXXII (BRASIL, 2020c).

De outra banda, o Ministério da Saúde passou a protelar a divulgação dos dados sobre a pandemia da COVID-19, alterando o formato do balanço diário da COVID-19, acabando por omitir dados de suma importância sobre a atuação do vírus, tendo retirado temporariamente do ar o site de divulgação dos números correlacionados à doença, da mesma forma que o Ministério alterou o funcionamento do aplicativo Coronavirus - SUS, não emitindo dados sobre o vírus (BRASIL, 2020d). Frente a isso, os partidos políticos Rede Sustentabilidade, Partido Comunista do Brasil - PCdoB e Partido Socialismo e Liberdade - PSOL, ajuizaram, junto ao STF, a Medida Cautelar na ADPF n. 690, que também teve como relator o Ministro Alexandre de Moraes.

Em síntese, sustentaram que ocorreu uma mudança injustificável na prática adotada pelo Ministério da Saúde no que tange à divulgação dos dados referentes à COVID-19, sendo que a retenção dessas importantíssimas informações inviabilizaria o acompanhamento do avanço do vírus no Brasil, acabando por atrasar a correta implantação da política pública sanitária de controle e prevenção da doença. Com isso, alegaram a violação a preceitos fundamentais da Constituição, sobretudo o direito à vida e à saúde, além do dever de transparência (BRASIL, 2020d).

Frente a isso e pelo grave risco de uma cessão abrupta do recolhimento e divulgação de dados epidemiológicos essenciais para a manutenção da análise da série histórica de evolução da pandemia no país, o STF concedeu parcialmente a Medida Cautelar na ADPF n. 690. Desse modo, foi determinado ao Ministro da Saúde em exercício que mantivesse, em sua integralidade, a divulgação diária dos dados epidemiológicos concernentes à pandemia, inclusive no sítio do Ministério da Saúde e com os números acumulados de ocorrências, exatamente conforme era procedido até então (BRASIL, 2020d).

Nesse aspecto, "a informação é elemento essencial e determinante de todos os campos do conhecimento" (MARIZ, 2012, p. 21). Por isso, contém suma importância em diversos campos da sociedade, sendo instrumento relevante para a criação de políticas públicas de qualidade, não apenas no ramo do direito à saúde e na atual crise sanitária vivenciada pelo Brasil e pelo mundo, mas também nos diversos ramos da sociedade provida de um Estado Democrático de Direito.

Por esse ângulo, o posicionamento do STF quanto à efetivação do direito à informação como forma de proteção ao direito à saúde na atual crise vivenciada, é firme ao destacar a fundamentalidade do acesso à informação em todas as circunstâncias. Não podendo o Estado restringir direitos fundamentais, principalmente em momentos de crise. As políticas de contingências dependem de informações para a sua ideal aplicabilidade e funcionamento, observando a proteção do direito à saúde, da vida e da dignidade da pessoa humana.

Nessa senda, entende-se pela jurisprudência estudada que o Supremo Tribunal Federal afirma que o direito à informação não pode ser limitado, sendo um importante pressuposto para a proteção sistêmica do direito à saúde, uma vez que a coleta de dados correlacionadas 
à COVID-19 constituem mecanismos essenciais para a tomada de decisões, alocação de recursos, efetividade de políticas públicas e ações de vigilância epidemiológicas.

Ainda, que enquanto a publicidade das informações são a regra, a não publicidade de determinada informação é a exceção, sendo permitida tão somente quando for benéfica ao interesse público, não podendo transformar a exceção — sigilo — em regra. Por fim, constata-se que o direito de acesso à informação age como pressuposto da garantia e da proteção de todo e qualquer direito fundamental, da eficácia e da eficiência de políticas públicas de qualquer natureza, enfatizando-se, aqui, o direito à saúde.

\section{CONSIDERAÇões FINAIS}

Em vista do maior desafio sanitário do século, o Brasil, assim como o mundo todo, tem assistido à evolução dos números de casos de óbitos e de infectados pela COVID-19, como consequência, denota-se diversas alterações na rotina da população e nas políticas de controle do novo vírus. Todas essas mudanças geram um ciclo de informações que inicia desde as testagens, estudos da atuação do vírus, hospitalizações, números de infectados, números de recuperados, números de óbitos, entre outros.

Nessa seara, o direito à saúde e o direito à informação são garantias fundamentais apresentadas pela Carta Magna de 1988 e regulamentados por dispositivos infraconstitucionais, cabendo ao Estado a obrigatoriedade de efetivá-los. Nessa dinâmica, tem-se circunstâncias em que nem sempre União, Estados e Municípios trabalham de forma a preservar e efetivar os respectivos direitos constitucionais, cabendo ao STF o papel de proteger e decidir a respeito dos conflitos criados dentro do Estado em relação aos princípios e normas fundamentais.

Dessa forma, este trabalho passou, de início, a analisar o direito à informação e sua correlação na proteção do direito à saúde, para, em seguida, observar o posicionamento do Supremo Tribunal Federal diante do fornecimento de dados correlacionados à COVID-19 por meio das ADIs n. 6351, 6347, 6353 e da Medida Cautelar na ADPF n. 690.

Com isso, tendo em consideração a problemática proposta no presente artigo, destaca-se que o Supremo Tribunal Federal posiciona-se no sentido de compreender que o direito à informação não pode ser limitado, sendo um importante pressuposto para a proteção sistêmica do direito à saúde, uma vez que a coleta de dados correlacionadas à COVID-19 constituem mecanismos essenciais para a tomada de decisões, alocação de recursos, efetividade de políticas públicas e ações de vigilância epidemiológicas. Ainda que a não publicidade específica de determinada informação somente poderá ser excepcional quando o interesse público assim determinar, não podendo transformar a exceção — sigilo — em regra.

Ademais, advoga-se, nesse sentido, que o direito de acesso à informação age como pressuposto de garantia do direito à saúde, sendo ambos os direitos além de deveres do Estado, muito mais, direitos dos cidadãos. Portanto, denota-se que a importância da pesquisa está direcionada ao fator de compreender e demonstrar como a proteção ao direito à saúde é sistêmica, abrangendo outros direitos previstos pelo ordenamento jurídico nacional. 


\section{REFERÊNCIAS}

ARAÚJO, L.A.D. et al. Curso de direito constitucional. $8^{\circ}$. ed. São Paulo: Saraiva, 2004.

BITENCOURT, C. M. RECK, J. R. Controle da transparência na contratação pública no Brasil - o acesso à informação como forma de viabilizar o controle social da administração pública. Revista do Direito (UNISC). Santa Cruz do Sul, v. 2, n. 49, p. 96-115, mai./ ago. 2016. Disponível em: https://online.unisc.br/seer/index.php/direito/article/download/7892/5125. Acesso em: 30 abr. 2021.

BRASIL. [Constituição, (1988)]. Constituição da República Federativa do Brasil. Brasília, DF: Presidência da República, [2020]. Disponível em: http://www.planalto.gov.br/ ccivil_03/constituicao/constituicao. Acesso em: 13 ago. 2020.

BRASIL. Decreto n. 7.724, de 16 de maio de 2012. Regulamenta a Lei ${ }^{\circ} 12.527$, de 18 de novembro de 2011, que dispõe sobre o acesso a informações previsto no inciso XXXIII do caput do art. $5^{\circ}$, no inciso II do $\S 3^{\circ}$ do art. 37 e no $\S 2^{\circ}$ do art. 216 da Constituição. Brasília, DF: Presidência da República, [2019]. Disponível em: http://www.planalto.gov. br/ccivil_03/_ato2011-2014/2012/decreto/d7724.htm. Acesso em: 10 ago. de 2020.

BRASIL. Lei 13.979, de 06 de fevereiro de 2020 (a). Dispões sobre as medidas para enfrentamento da emergência de saúde pública de importância internacional decorrente do coronavírus responsável pelo surto de 2019. Brasília, DF: Presidente da República, [2020]. Disponível em: http://www.planalto.gov.br/ccivil_03/_ato2019-2022/2020/lei/113979.htm. Acesso em: 10 ago. 2020.

BRASIL. Lei 12.527, 18 de novembro de 2011. Regula o acesso a informações previsto no inciso XXXIII do art. $5^{\circ}$, no inciso II do § 30 do art. 37 e no $\S 20$ do art. 216 da Constituição Federal; altera a Lei no 8.112, de 11 de dezembro de 1990; revoga a Lei no 11.111, de 5 de maio de 2005, e dispositivos da Lei no 8.159, de 8 de janeiro de 1991; e dá outras providências. Brasília, DF: Presidência da República, [2019]. Disponível em: http://www. planalto.gov.br/ccivil_03/_ato2011-2014/2011/lei/112527.htm. Acesso em: 14 jul. 2020.

BRASIL. Controladoria-Geral da União. Governo estabelece alterações em prazos de atendimento da LAI. Gov.br, Brasília, DF, 23 mar. 2020 (b). Disponível em: https://www.gov. $\mathrm{br} / \mathrm{cgu} / \mathrm{pt}$-br/assuntos/noticias/2020/03/governo-estabelece-alteracoes-em-prazos-de-atendimento-da-lai. Acesso em: 10 ago. 2020.

BRASIL. Supremo Tribunal Federal. Medida Cautela de Descumprimento de Preceito Fundamental n. 690 Distrito Federal. Sequência de atos do Poder Executivo Federal que restringiram a publicidade dos dados relacionados à covid-19, em clara violação a preceitos fundamentais da Constituição Federa. [...] Requerentes: Rede Sustentabilidade, Partido Socialismo e Liberdade (P-SOL) e Partido Comunista do Brasil. Intimado: Ministro de Estado 
da Saúde. Relator: Alexandre de Moraes, 08 de junho de 2020 (d). Disponível em: http:// www.stf.jus.br/arquivo/cms/noticiaNoticiaStf/anexo/ADPF690cautelar.pdf. Acesso em: 13 ago. 2020.

BRASIL. Supremo Tribunal Federal. Referendo na Medida Cautelas na Ação Direta de Inconstitucionalidade n. 6.351, 6.347 e 6.353 Distrito Federal. CONSTITUCIONAL E ADMINISTRATIVO. Restrições genéricas e abusivas à garantia constitucional de acesso à informação. [...] Requerente: Conselho Federal da Ordem dos Advogados do Brasil. Intimado: Presidente da República. Relator: Min. Alexandre de Moraes, 30 de abril de 2020 (c). Disponível em: http://portal.stf.jus.br/processos/detalhe.asp?incidente=5881853. Acesso em: 10 ag. 2020.

CANOTILHO, José J. G. et al. Constituição da república portuguesa anotada. $3^{\circ}$. ed. Coimbra: Coimbra Editor, 1993.

CURY, L. T. Direito fundamental à saúde: evolução, normatização e efetividade. Rio de Janeiro: Lúmen Júris, 2005.

FERRARI, C.C. et al. O direito à informação como direito fundamental ao Estado Democrático. Rev. Direitos Sociais e Políticas Públicas (UNIFAFIBE). Bebedouro, SP, ISSN 2318-5732, v.4, n. 2, p. 124-124, jan./jul., 2016. Disponível em: http://www.unifafibe.com. br/revista/. Acesso em: 10 de ago. 2020.

HABERMAS, J. Direito e Democracia: entre facticidade e validade. Tradução: Flávio B. Siebeneichler. Rio de Janeiro, 2012.

HEINEN, J. Comentários à Lei de acesso à informação: Lei $n^{\circ} 12.257 / 2011.2^{\circ}$. ed. rev. e atual. Belo Horizonte: Fórum, 2015.

HOLMES JÚNIOR, O. W. The Mind and Faith os Justice Holmes: His Speeches, Essays, Letters, and Judicial Opinions. 2. ed. New York: Dover, 1988.

KAHN, A. W. Prefácio. In: MEDEL, T. Liberdade de informação: Um Estudo de direito comparado. $2^{\circ}$. ed. Brasília: UNESCO, 2009. Disponível em: https://www.ufmg.br/ proex/cpinfo/cidadania/wp-content/uploads/2014/04/Liberdade-de-informa\%C3\%A7\%C3\%A3o_um-estudo-de-direito-comparado.pdf. Acesso em: 29 nov. 2021.

KRAMER, G. P. et al. O acesso à informação como fonte de conhecimento e transparência pública a luz da Lei n. 12.527/2011: O caso da Justiça Federal da cidade do Rio Grande. Rev. Ágora. ISSN 0103-3557, Florianópolis, v. 25, n. 51, p. 354-376, jul./dez., 2015. Disponível em: http://www.periodicos.unc.br/index.php/agora. Acesso em: 10 ago. 2020. 
LIMBERGER, T. Transparência administrativa e novas tecnologias: o dever de publicidade, o direito a ser in-fmado e o princípio democrático. Rev. Do Ministério Público do RS. Porto Alegre, v. 25, n. 60, ago.2007/abr.2008, p. 47-65, 2008. Disponível em: https:/www. mprs.mp.br/biblioteca/revistamp. Acesso em: 10 ago. 2020.

MAAS, R. H., BOSA, Anderson Carlos. O fornecimento de medicamentos sem registro na ANVISA: Uma análise frente aos critérios estabelecidos pelo STF. Rev. Direitos Sociais e Políticas Públicas (UNIFAFIBE). ISSN 2318-57-32, v. 8, n. 2, p. 340-370, 2020. Disponível em: http://www.unifafibe.com.br/revista/index.php/direitos-sociais-politicas-pub/ issue/view/39. Acesso em: 13 ago. 2020.

MARIZ, A. C. A. A Informação na Internet. Arquivos públicos brasileiros. Rio de Janeiro, 2012.

MARTINS JÚNIOR, Wallace Paiva. Transparência Administrativa: publicidade, motivação e participação popular. São Paulo: Saraiva, 2010.

MENDEL, T. Liberdade de informação: um estudo de direito comparado. $2^{\circ}$ ed. Brasília: UNESCO, 2009.

MORAES, A. de. Direito constitucional. 13. ed. São Paulo: Atlas, 2003.

NOVELINO, M. Manual de direito constitucional. $8^{\circ}$ ed. São Paulo: Método, 2013.

SEABRA, S.N. et al. Lei de Acesso à Informações: uma análise dos fatores de sucesso da experiência do poder executivo federal. Rev. de Administração Municipal - IBAM. Rio de Janeiro, v. 58, n. 282. p. 18-26, 2012. Disponível em: https:/issuu.com/ibam/docs/ ibam_282-completa. Acesso em: 13 ago. 2020.

SILVA, J. A. da. Curso de Direito Constitucional Positivos. 37 ed. São Paulo: Malheiros Editores, 2014.

STROPPA, T.. As dimensões constitucionais do direito de informação e o exercício da liberdade de informação jornalística. Belo Horizonte: Fórum, 2010.

UCHÔA, S.B.B. et al. Coronavírus (COVID-19): Um exame constitucional e ético das medidas previstas na Lei n. 13.979, de 06 de fevereiro de 2020. Rev. Cadernos de Prospecção. Salvador, v. 13, n.2, Edição Especial, p. 441-458, abril, 2020. Disponível em: https:// portalseer.ufba.br/index.php/nit/article/view/36163/20967. Acesso em: 13 ago. 2020. 


\section{DADOS DOS AUTORES}

\section{Anderson Carlos Bosa}

Acadêmico do curso de Direito da Universidade de Santa Cruz do Sul, UNISC. E-mail: andersonn.bosa@gmail.com

\section{Rosana Helena Maas}

Pós-doutora em Direito pela Universität Salzburg, Áustria. Doutora em Direito pelo Programa de Pós-Graduação em Direito, Mestrado e Doutorado, da Universidade de Santa Cruz do Sul - UNISC, com doutorado sanduíche na Ernst-Moritz-Arndt-Universität Greifswald, Rechts und Staatswissenschaftliche Fakultät, Greifswald, Alemanha. E-mail: rosanamas@unisc.br

Submetido em: 4-5-2021

Aceito em: 25-10-2021 